\title{
Desfolha precoce como estratégia de controle da podridão de Botrytis cinerea na videira Cabernet Sauvignon em regiões de altitude
}

\author{
Douglas André Würz ${ }^{1}$, Alberto Fontanella Brighenti ${ }^{2}$, Ricardo Allebrandt ${ }^{1}$, José Luiz Marcon Filho ${ }^{3}$, Betina Pereira \\ de Bem ${ }^{1}$ Jerônimo Vieira Araújo Filho ${ }^{4}$, Leo Rufato ${ }^{1}$, Aike Anneliese Kretzschmar ${ }^{1}$
}

\begin{abstract}
${ }^{1}$ Universidade do Estado de Santa Catarina, Centro de Ciências Agrárias - UDESC/CAV, Avenida Luiz de Camões 2090, Bairro Conta Dinheiro, Lages-SC, 88520-000. douglaswurz@hotmail.com, ricardoudesc@yahoo.com.br, betadebem@yahoo.com.br, leoruffato@yahoo.com.br, aikeanneliese@yahoo.com.br; ${ }^{2}$ Empresa de Pesquisa Agropecuária e Extensão Rural de Santa Catarina, Estação Experimental de São Joaquim, Rua João Araújo Lima, no 102, Bairro Jardim Caiçara, São Joaquim - SC, 88600000. albertobrighenti@epagri.sc.gov.br ; ${ }^{3}$ Engenheiro Agrônomo, Dr. em Produção Vegetal, Supervisor de Viticultura Vinícola Legado, Rod. Raul Azevedo de Macedo, 5800 - CEP 83606-482, Campo Largo-PR. marconfilho_jl@yahoo.com. ${ }^{4}$ Universidade Federal de Pelotas, Faculdade de Agronomia “Eliseu Maciel”, Departamento de Fitossanidade, Campus
\end{abstract} Universitário, S/N - Capão do Leão, RS, 96160-000. jeronimo.vieira@ufpel.edu.br

Autor para correspondência: Douglas André Würz (douglaswurz@hotmail.com)

Data de chegada: 05/10/2016. Aceito para publicação em: 16/02/2017.

$10.1590 / 0100-5405 / 169870$

\section{RESUMO}

Würz, D.,A., Brighenti, A.F.; Allebrandt, R.; Marcon Filho, J.L.; Bem, B.P.; Araújo Filho, J.V.; Rufato, L.; Kretzschmar, A.A.. Desfolha precoce como estratégia de controle da podridão de Botrytis cinerea na videira Cabernet Sauvignon em regiões de altitude. Summa Phytopathologica, v.43, n.2, p.111-117, 2017.

Botrytis cinerea é um dos mais importantes patógenos da videira nas regiões de altitude em Santa Catarina. O presente trabalho objetivou avaliar a influência de diferentes épocas de desfolha no progresso da podridão de B. cinerea na videira Cabernet Os ensaios foram conduzidos nas safras 2014/2015 e 2015/2016, em um vinhedo comercial, situado a 1230m (a.n.m.), no munícipio de São Joaquim, SC ( $28^{\circ} 17^{\prime} 39^{\prime}$ ' S e $49^{\circ} 55^{\prime} 56^{\prime \prime}$ W). Foi utilizado a variedade Cabernet Sauvignon, enxertada sobre o porta-enxerto Paulsen 1103, conduzida em espaldeira, com espaçamento de $3,0 \mathrm{~m}$ x $1,5 \mathrm{~m}$ e cobertura anti-granizo. Os tratamentos consistiram na realização da desfolha nos estádios fenológicos: plena florada, grão chumbinho, grão ervilha, virada de cor, 15 dias após a virada de cor e plantas não submetidas ao manejo da desfolha. A doença foi quantificada quinzenalmente nos cachos, no início dos primeiros sintomas até a colheita. As curvas de progresso da doença foram elaboradas e comparadas de acordo com: início do aparecimento dos sintomas, tempo para atingir a máxima incidência e severidade da doença, incidência e severidade máxima da doença, área abaixo da curva de progresso da incidência e severidade da doença. Os resultados desse estudo evidenciam que desfolhas precoces devem ser recomendadas, como estratégia de manejo de controle de $B$. cinerea da videira Cabernet Sauvignon cultivada em regiões de elevada altitude de Santa Catarina.

Palavras-chave: Podridão cinzenta, manejo do vinhedo, manejo integrado de doenças, epidemiologia vegetal.

\section{ABSTRACT}

Würz, D.,A., Brighenti, A.F.; Allebrandt, R.; Marcon Filho, J.L.; Bem, B.P.; Araújo Filho, J.V.; Rufato, L.; Kretzschmar, A.A.. Early leaf removal as a strategy to control Botrytis cinerea rot in Cabernet Sauvignon grapevine at high altitude regions. Summa Phytopathologica, v.43, n.2, p.111$117,2017$.

Botrytis cinerea is one of the most important pathogens in the highlands of Santa Catarina State. This study aimed to evaluate the influence of different times of leaf removal on the progress of $B$. cinerea rot in Cabernet Sauvignon grapevine. Assays were conducted in the 2014/2015 and 2015/2016 growing seasons in a commercial vineyard located at $1230 \mathrm{~m}$ (a.s.1.) in São Joaquim Municipality, Santa Catarina State ( $28^{\circ} 17^{\prime} 39^{\prime \prime} \mathrm{S}$ and $\left.49^{\circ} 55^{\prime} 56^{\prime \prime} \mathrm{W}\right)$. The variety Cabernet Sauvignon was grafted on Paulsen 1103 rootstock, conducted in vertical shooting positioning, $3.0 \mathrm{~m} \times 1.5 \mathrm{~m}$ spacing, and covered with hail protection net. Treatments consisted in leaf removal at the phenological stages: full bloom, buckshot berries, pea-sized berries, veraison, 15 days after veraison and plants not subjected to leaf removal. The disease was biweekly measured in bunches from the first symptoms to harvest. Disease progress curves were elaborated and compared according to: beginning of symptoms, time to maximum disease incidence and severity, maximum disease incidence and severity, and area under the disease incidence and severity progress curve. Results evidenced that early leaf removal should be recommended as management strategy to control B. cinerea in Cabernet Sauvignon grapevine grown in the highlands of Santa Catarina.

Keywords: Botrytis bunch rot, canopy management, integrated pest management, plant disease epidemiology.

A elaboração de vinhos finos nas regiões de altitude, em Santa Catarina, é relativamente recente, com menos de 15 anos de história, quando comparadas com outras regiões produtoras. Portanto a maioria das técnicas de manejo empregadas nos vinhedos é baseada nas experiências de outras regiões de produtores e técnicos (4). Além disso, em comparação as demais espécies frutíferas, a videira é uma planta exigente em tratos culturais. A realização de diversas atividades de manejo do dossel pode estar voltada para formação da planta e ramos equilibrados e para a melhoria da qualidade da uva (13). Dentre os manejos do dossel vegetativo da videira, podemos destacar a desfolha, que é uma prática cultural realizada na região dos cachos durante o período vegetativo da videira, com objetivo de modificar a qualidade 
da uva (20). Além de propiciar uma melhor maturação da uva, a desfolha torna-se um importante método de controle para o controle de Botrytis cinerea Pers. O desenvolvimento de $B$. cinerea é fortemente influenciado pelo microclima na zona dos cachos, que através da desfolha pode ser modificado, permitindo melhor aplicação de produtos fitossanitários, menor período de molhamento foliar, e aumento da camada epiticular das bagas e, assim, reduzir o desenvolvimento da $B$. cinerea $(19,29)$. Nesse contexto, as práticas vitícolas podem ter efeitos pronunciados sobre o desenvolvimento da doença, e em um sistema de manejo integrado de doenças, devem ser consideradas para uma produção adequada (1).

Em muitos países $B$. cinerea é considerado o mais importante patógeno causador de podridões de cachos (17). As condições climáticas catarinenses são favoráveis ao desenvolvimento de várias doenças, devido a elevadas precipitações, e temperaturas favoráveis (7), tornando o controle cultural, através do manejo do dossel vegetativo, fundamental para redução dos danos causados pela doença. A umidade relativa do ar é o fator mais importante para ocorrer a infecção. Quanto à temperatura, a mais adequada para a germinação dos conídios é de $25^{\circ} \mathrm{C}$. A infecção de um modo geral se dá a partir das cicatrizes deixadas pela queda das peças florais, sépalas, pétalas e estames ou por outros ferimentos (8).

No passado, a estratégia de controle da $B$. cinerea baseava-se apenas na pulverização de fungicidas. (23). No entanto, para o controle deve-se utilizar uma série de medidas preventivas, tais como proporcionar uma boa aeração e insolação através da exposição adequada; aplicação de tratos culturais como a desfolha, poda verde e adubação nitrogenada adequada (27). Ainda de acordo com Molitor et al. (17) e Molitor et al. (18), medidas culturais que resultam em maior exposição solar e ventilação na região dos cachos, como o manejo da desfolha, são ferramentas eficientes na estratégias de controle da $B$. cinerea nos cachos da videira.

Sendo a variedade Cabernet Sauvignon, variedade com maior área cultivada em Santa Catarina (4) e a necessidade de adoção de uma série de medidas adicionais para o manejo da doença, o presente trabalho teve como objetivo comparar a eficiência de diferentes épocas de desfolha no controle da $B$. cinerea na variedade Cabernet Sauvignon cultivada em regiões de altitude de Santa Catarina.

\section{MATERIAL E MÉTODOS}

Os experimentos foram conduzidos nas safras 2014/2015 e 2015/2016, em um vinhedo comercial, (28 $18^{\circ}$ ' $39^{\prime \prime} \mathrm{S}$ e $49^{\circ} 55^{\prime} 56^{\prime \prime} \mathrm{O}$; $1.230 \mathrm{~m}$ de altitude), no município de São Joaquim, Santa Catarina. O clima da região é classificado como ‘Frio, Noites Frias e Úmido', Índice Heliotérmico de 1,714, precipitação pluvial média anual de 1,621mm e a umidade relativa do ar média anual de $80 \%$ (25). Foi utilizado um vinhedo de Cabernet Sauvignon enxertada sobre porta-enxerto 'Paulsen 1103'. O vinhedo é cultivado em espaçamento de plantas de 3,0 x 1,5m, em filas dispostas no sentido N-S, conduzidas em espaldeira, podadas em cordão esporonado duplo, a 1,2m de altura e cobertas com tela de proteção anti-granizo.

Os tratamentos consistiram na realização da desfolha, expondo a região dos cachos em seis diferentes estádios fenológicos, descritos por Baillod \& Baggiollini (2): plena florada, grão chumbinho, grão ervilha, virada de cor, 15 dias após a virada de cor e plantas não submetidas ao manejo da desfolha.

Os dados meteorológicos foram obtidos a partir de Estação Meteorológica Automática Telemétrica do Centro de Informações de Recursos Ambientais e de Hidrometeorologia de Santa Catarina
(EPAGRI/CIRAM), localizada na Estação Experimental da EPAGRI em São Joaquim. Os parâmetros meteorológicos foram: temperatura média do ar $\left({ }^{\circ} \mathrm{C}\right)$ e precipitação pluvial $(\mathrm{mm})$ diária durante os meses de novembro a abril das safras 2014/2015 e 2015/2016, que coincidem com o intervalo de estádios fenológicos plena florada e colheita (Figura 1).

A incidência de $B$. cinerea nos cachos foi obtida pela avaliação visual, sendo verificada a presença ou ausência de sintomas/sinais da doença. A avaliação foi realizada em todos os cachos presentes em cinco plantas por parcela. Sendo a incidência calculada pela porcentagem de cachos que apresentavam ao menos uma lesão em relação ao número total de cachos. Para a severidade de $B$. cinerea, as avaliações iniciaram ao surgimento do primeiro sintoma/sinal, em intervalos de quinze dias. Foram marcados 30 cachos/parcela, tomados aleatoriamente, e as avaliações foram realizadas com escala diagramática de Hill et al., (12): 1, 5, 10, 15, 20, 30, 40, 50, 60, 70, 80 e 90\%. Durante a safra 2015 foram realizadas cinco avaliações, e na safra 2016, quatro avaliações da doença durante o ciclo da videira.

Com os dados obtidos da $B$. cinerea da videira foram traçadas curvas de progresso da incidência e da severidade, e a epidemia foram comparadas em relação ao: início do aparecimento dos sintomas (IAS) (dias); tempo para atingir a máxima incidência e severidade da doença (TAMID e TAMSD) (dias); valor máximo da incidência (Imax) (\%) e severidade (Smax) (\%); área abaixo da curva de progresso da incidência (AACPI) e da severidade (AACPS). Para o cálculo da Área Abaixo da Curva de Progresso de Doença (AACPD) utilizou-se a fórmula: AACPD $=\Sigma((\mathrm{Yi}+\mathrm{Yi}+1) / 2)(\mathrm{ti}+1-\mathrm{ti})$, onde $\mathrm{Y}$ representa a intensidade (incidência e severidade) da doença, t o tempo e i o número de avaliações no tempo (5).

O delineamento experimental utilizado foi o de blocos ao acaso, com quatro blocos e dez plantas por repetição. Os dados das médias de incidência da doença foram transformados pelo arco seno da raiz quadrada para normalização da distribuição estatística. As médias foram submetidas à análise de variância (ANOVA) e a detecção de diferenças significativas entre os tratamentos foi obtida através do teste Scott Knott $(\alpha=0.05)$, utilizando o programa estatístico Sisvar 5.6.

\section{RESULTADOS E DISCUSSÃO}

A temperatura média, umidade relativa do ar e o volume de chuvas durante as durante o ciclo vegetativo da videira (Novembro a Abril) foram similares nas duas safras avaliadas, apresentando no ciclo $2014 / 2015\left(16^{\circ} \mathrm{C}, 82,1 \%\right.$ e $\left.1019 \mathrm{~mm}\right)$ e no ciclo $2015 / 2016\left(16,8^{\circ} \mathrm{C}\right.$, $83,6 \%$ e $953,4 \mathrm{~mm}$ ) (Figura 1). Combinação de altos volumes de chuvas, alta umidade relativa são fatores que favorecem o aparecimento da doença, principalmente na primavera e verão (6), além disso, para desenvolvimento da doença tem-se a faixa de $15-23^{\circ} \mathrm{C}$, como temperatura ótima $(9,26)$.

As avaliações tiveram início no dia 15 de janeiro e 22 de janeiro para as safras 2015 e 2016, respectivamente, sendo realizados quinzenalmente até a colheita. Esses períodos antecederam em sete dias o início da maturação da variedade Cabernet Sauvignon, pois apesar das infecções de $B$. cinerea ocorreram a partir da florada, seus sintomas são visíveis apenas no início da maturação da uva, podendo no período de latência colonizar cada vez mais a baga sem a exteriorização dos sintomas (16). Nenhuma das épocas de desfolha proporcionou atraso na epidemia, como pode ser visto pelos valores de IAS, TAMID e TAMDS (Tabela 1). No entanto, a taxa de progresso da doença foi diferente entre as épocas de desfolha, devido ao microclima formado em cada época de desfolha, o que acarretou em diferenças na intensidade da doença. 

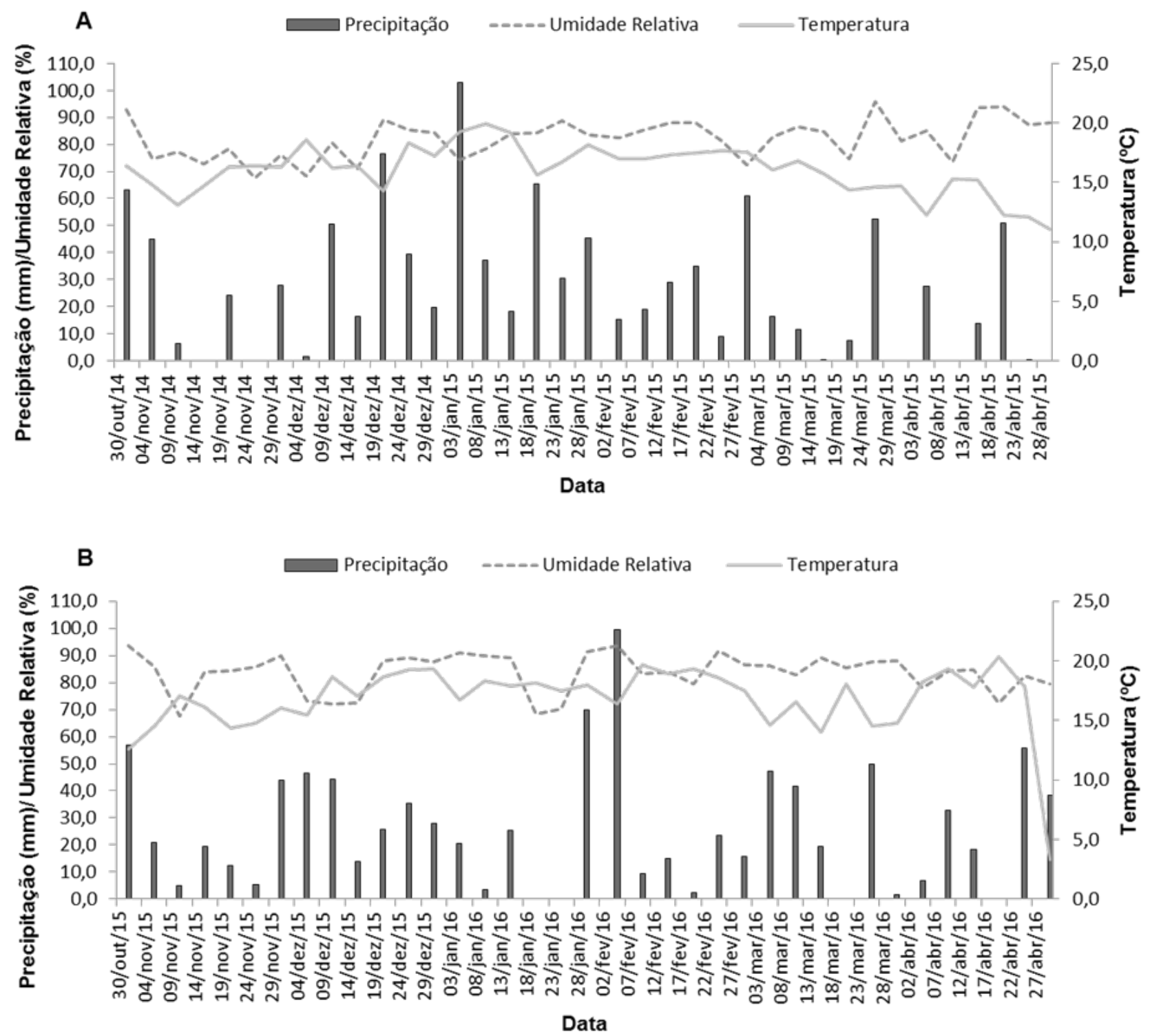

Figura 1. Precipitação pluvial acumulada (mm), umidade relativa do ar $(\%)$ e temperatura média do ar $\left({ }^{\circ} \mathrm{C}\right)$ em São Joaquim/SC durante as safras 2015 (A) e 2016 (B).

Tabela 1. Início do aparecimento dos sintomas (IAS) (dias após a primeira avaliação), tempo para atingir a máxima incidência da doença (TAMID dias) e tempo para atingir a máxima severidade da doença (TAMSD) na videira Cabernet Sauvignon cultivada em regiões de elevada altitude de Santa Catarina durante as safras 2015 e 2016

\begin{tabular}{|c|c|c|c|c|c|}
\hline \multirow{2}{*}{ Época de desfolha } & \multicolumn{2}{|c|}{ IAS (dias) } & \multicolumn{2}{|c|}{ TAMID (dias) } & \multirow{2}{*}{$\frac{\text { TAMSD (dias) }}{2016}$} \\
\hline & 2015 & 2016 & 2015 & 2016 & \\
\hline Plena Florada & $15 \mathrm{~ns}$ & $15 \mathrm{~ns}$ & $60 \mathrm{~ns}$ & $55 \mathrm{~ns}$ & $56 \mathrm{~ns}$ \\
\hline Grão Ervilha & 15 & 15 & 63 & 60 & 58 \\
\hline Virada de Cor & 15 & 15 & 56 & 60 & 60 \\
\hline CV (\%) & 2,5 & 3,0 & 23,3 & 20,1 & 5,6 \\
\hline
\end{tabular}

*Médias seguidas da mesma letra, na coluna, não diferem entre si pelo teste Scott Knott a 5\% de probabilidade de erro. ns = não significativo pela análise de variância (ANOVA) a 5\% de probabilidade de erro. 
Verificou-se influência das diferentes épocas de desfolha na incidência e severidade da podridão de $B$. cinerea nas duas safras avaliadas (Tabela 2). As desfolhas realizadas precocemente, nos estádios fenológicos plena florada, grão chumbinho e grão ervilha, apresentaram a menor incidência da doença $(74,77,78 \%$ e 34,43 e $42 \%$ nas safras 2015 e 2016, respectivamente). Enquanto plantas não submetida a desfolha, ou desfolhadas tardiamente, nos estádios fenológicos virada de cor e 15 dias após a virada de cor, apresentam valores de incidência da doença superiores a $90 \%$ e $70 \%$, nas safras 2015 e 2016, respectivamente. A incidência da podridão de $B$. cinerea foi superior na safra 2014/2015, muito provavelmente devido ao maior volume de chuvas na época crítica de infecção (floração). Além disso, verificou-se elevação da temperatura média a partir do estádio fenológico plena florada na safra 2014/2015, favorecendo assim a ocorrência de $B$. cinerea (28).

A severidade da doença apresentou comportamento semelhante, cujas desfolhas realizadas nos estádios fenológicos plena florada e grão chumbinho apresentaram os menores valores de severidade da doença (19 e 15\%, respectivamente) na safra 2014/2015, e nos menores valores de severidade da doença nos estádios fenológicos plena florada, grão chumbinho e grão ervilha (11, 7 e 10\%, respectivamente) na safra 2015/2016 (Tabela 2).

A viticultura passa por uma necessidade em utilizar formas de cultivos mais sustentáveis (3), e consequentemente reduzir o uso de produtos químicos de controle de doenças. Nesse contexto, as práticas de manejo são fundamentais, tais como desbrote (15), desponte (18) e a desfolha $(10,14)$, esse último manejo, no presente estudo apresentando os efeitos desejados no controle da doença, conforme verificado pelos menores valores incidência e severidade de $B$. cinerea quando a videira Cabernet Sauvignon foi submetida ao manejo da desfolha precocemente.

Verificaram-se diferenças estatisticamente significativas entre as diferentes épocas de desfolha quanto à área abaixo da curva de progresso da incidência da doença (AACPID) nas safras 2014/2015 e 2015/2016, e área abaixo da curva de progresso da severidade da doença (AACPSD) nas safras 2014/2015 e 2015/2016. A AACPID apresentou comportamento similar a incidência total da doença, na qual, as desfolhas realizadas precocemente, nos estádios fenológicos plena florada, grão chumbinho e grão ervilha apresentaram valores inferiores nas duas safras avaliadas.

Na safra 2014/2015, verificou-se para a AACPSD o menor valor para as desfolhas realizadas precocemente, ou seja, antes do estádio fenológico virada de cor. A desfolha realizada no estádio fenológico grão chumbinho apresentou o menor valor de AACPSD $(262,8)$, seguidos pelas desfolhas realizadas nos estádios fenológicos plena florada e grão ervilha, que apresentaram AACPSD de 346,2 e 365,9, respectivamente. Já as plantas não submetidas ao manejo da desfolha, ou então, desfolhas nos estádios fenológicos virada de cor e 15 dais após a virada de cor apresentam os maiores valores de AACPSD (791,3, 753,9 e 763,9, respectivamente). Já na safra 2015/2016, verificou-se o menor valor para a desfolha realizada no estádio fenológico grão chumbinho $(164,5)$, seguido pelas desfolhas realizadas nos estádios fenológicos grão ervilha $(241,6)$ e plena florada $(263,8)$. Observa-se para plantas não submetidas ao manejo da desfolha, ou desfolhadas tardiamente, nos estádios fenológicos virada de cor e 15 dias após a virada de cor, valores superiores de AACPSD em relação às desfolhas realizadas precocemente (Tabela 2).

Durante a safra 2014/2015, verificou-se um aumento significativo da incidência doença nos trinta primeiros dias de avaliação (Figura 2), que coincidiu com elevados volumes e dias de chuva em um intervalo de quarenta dias após o início da maturação da uva Cabernet Sauvignon (Figura 1). Contudo, a partir do $45^{\circ}$ dia de avaliação da doença, verificou-se uma diminuição do volume e dos dias com chuva, e consequentemente houve uma estabilização do progresso da doença (Figura 2). Além disso, após o $45^{\circ}$ da avaliação da doença houve diminuição da temperatura média do ar, desfavorável a epidemia da doença. Já para o progresso da severidade da $B$. cinerea, verificou-se crescimento linear no intervalo compreendido do início das avaliações até os 60 dias após a primeira avaliação, e a partir do $60^{\circ}$ de avaliação, houve um aumento da severidade para todas as épocas de desfolha, no entanto, as desfolhas realizadas precocemente, até o estádio fenológico virada de cor, propicia menor evolução da epidemia da doença, resultando no momento da colheita, valores inferiores de AACPSD em relação às plantas não submetidas ao manejo da desfolha, ou desfolhadas nos estádios fenológicos virada de cor e 15 dias após a virada de cor. De acordo com a Figura 1. verificou-se no período avaliado teores de umidade relativa do ar acima de $70 \%$, e elevado número de dias de chuva, e no $60^{\circ}$ dia após o início das avaliações, houve um pico de umidade relativa e ocorrência de precipitação, o que resultou no aumento do progresso da severidade da $B$. cinerea.

Já para a safra 2015/2016, verificou-se um aumento do progresso da doença constante até o $30^{\circ}$ dia após a primeira avaliação, contudo

Tabela 2. Incidência máxima (Imáx) (\%), severidade máxima (Smáx) (\%), área abaixo da curva de incidência da doença (AACPID) e área abaixo da curva de progresso da doença (AACPSD) na videira Cabernet Sauvignon cultivada em regiões de elevada altitude de Santa Catarina durante as safras 2015 e 2016.

\begin{tabular}{cccccccccc}
\hline \multirow{2}{*}{ Época de Desfolha } & \multicolumn{2}{c}{ Imáx (\%) } & \multicolumn{2}{c}{ Smáx (\%) } & \multicolumn{2}{c}{ AACPID } & \multicolumn{2}{c}{ AACPSD } \\
\cline { 2 - 7 } & 2015 & 2016 & 2015 & 2016 & 2015 & 2016 & 2015 & 2016 \\
\hline Plena Florada & $74 \mathrm{a}$ & $34 \mathrm{a}$ & $19 \mathrm{a}$ & $11 \mathrm{a}$ & $4217,5 \mathrm{a}$ & $1445,6 \mathrm{a}$ & $346,2 \mathrm{~b}$ & $263,8 \mathrm{~b}$ \\
Grão Chumbinho & $77 \mathrm{a}$ & $43 \mathrm{a}$ & $15 \mathrm{a}$ & $7 \mathrm{a}$ & $4370,4 \mathrm{a}$ & $1375,5 \mathrm{a}$ & $262,8 \mathrm{a}$ & $164,5 \mathrm{a}$ \\
Grão Ervilha & $78 \mathrm{a}$ & $42 \mathrm{a}$ & $33 \mathrm{~b}$ & $10 \mathrm{a}$ & $4106,1 \mathrm{a}$ & $1630,0 \mathrm{a}$ & $365,9 \mathrm{~b}$ & $241,6 \mathrm{~b}$ \\
Virada de Cor & $90 \mathrm{~b}$ & $78 \mathrm{~b}$ & $45 \mathrm{c}$ & $19 \mathrm{~b}$ & $5155,3 \mathrm{~b}$ & $2011,4 \mathrm{~b}$ & $753,9 \mathrm{c}$ & $600,5 \mathrm{~d}$ \\
15 dias após Virada de Cor & $92 \mathrm{~b}$ & $74 \mathrm{~b}$ & $54 \mathrm{c}$ & $20 \mathrm{~b}$ & $5515,1 \mathrm{~b}$ & $2824,0 \mathrm{~b}$ & $763,9 \mathrm{c}$ & $506,1 \mathrm{c}$ \\
Sem Desfolha & $97 \mathrm{~b}$ & $73 \mathrm{~b}$ & $56 \mathrm{c}$ & $22 \mathrm{~b}$ & $5539,4 \mathrm{~b}$ & $2399,2 \mathrm{~b}$ & $791,3 \mathrm{c}$ & $491,8 \mathrm{c}$ \\
\hline CV (\%) & 12,2 & 10,8 & 18,3 & 15,4 & 12,9 & 11,6 & 10,1 & 8,4 \\
\hline
\end{tabular}

*Médias seguidas da mesma letra, na coluna, não diferem entre si pelo teste Scott Knott a 5\% de probabilidade de erro. 

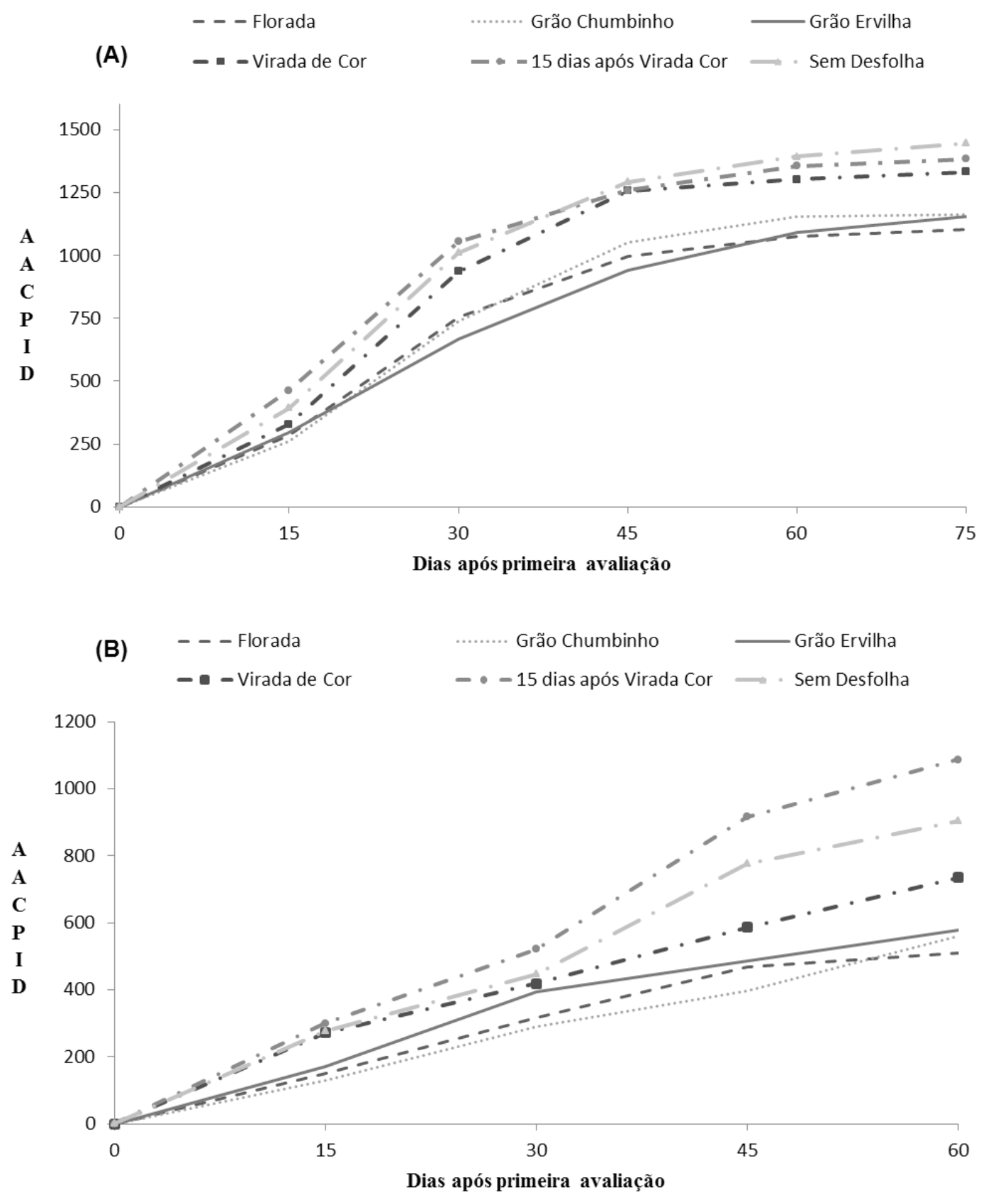

Figura 2. Curva de progresso da incidência da doença (AACPID) na videira cultivar Cabernet Sauvignon cultivada em regiões de elevada altitude de Santa Catarina, durante as safras 2015 (A) e 2016 (B).

a partir do $30^{\circ}$ verificou-se um aumento intensivo do progresso da incidência da doença (Figura 2), coincidindo com os maiores valores e dias com chuva durante a safra $2016\left(30^{\circ}\right.$ ao $60^{\circ}$ dia após a primeira avaliação da doença). De acordo com a Figura 3, para o progresso da severidade, como houve um menor número de dias com chuva até o $30^{\circ}$ de avaliação da doença, o progresso da severidade foi lento, no entanto, a partir do $30^{\circ}$ dia de avaliação verificou-se um aumento significativo do progresso da severidade da doença, que assim como a incidência da doença, coincidiu com o período de maior volume e dias com chuva, favorecendo assim um aumento da epidemia da doença. Além disso, bagas imaturas são altamente resistentes a $B$. cinerea, entre o período de frutificação de virada de cor (11), em comparação a bagas maduras ou em amadurecimento, onde as infecções são mais severas e os sintomas são visíveis (23). Portanto, condições favoráveis de ambiente e condições biológicas são condições fundamentais para o desenvolvimento da doença e são de fundamental importância para determinar as estratégias de controle da doença.

Nas duas safras avaliadas, tanto para o progresso da incidência quanto para o progresso da severidade, verificou-se, em condições favoráveis da doença (temperatura média de $15-25^{\circ} \mathrm{C}$, umidade relativa alta, e volume e dias de chuva), que as desfolhas realizadas precocemente, nos estádios fenológicos plena florada, grão chumbinho e grão ervilha apresentaram menor progresso da doença, quando comparado a plantas não submetidas ao manejo da desfolha, ou 


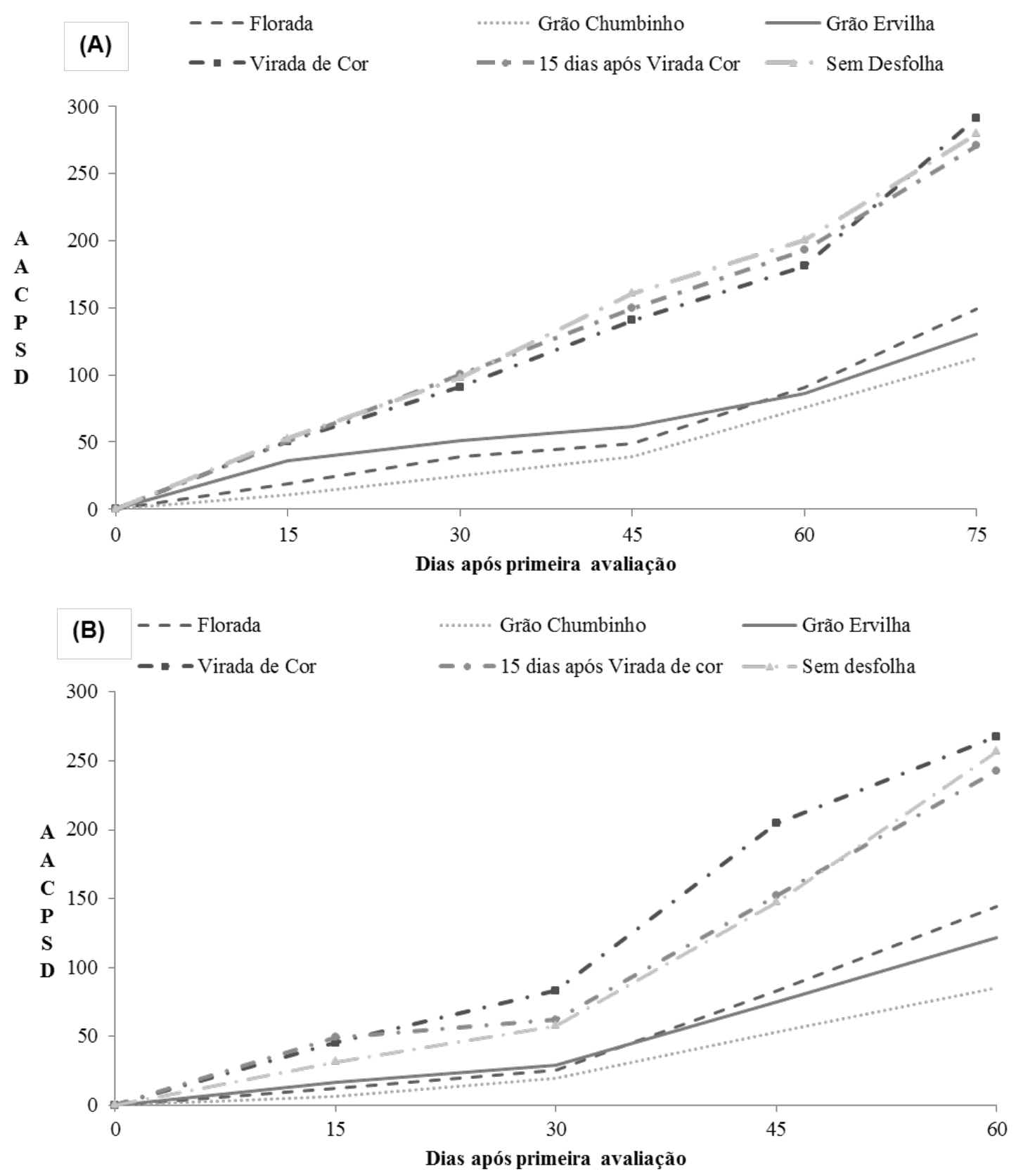

Figura 3. Curva de Progresso da severidade (AACPSD) do mofo cinzento na cultivar de videira Cabernet Sauvignon cultivada em regiões de elevada altitude de Santa Catarina, durante as safras 2015 (A) e 2016 (B).

desfolhas tardiamente, nos estádios fenológicos virada de cor e 15 dias após a virada de cor, evidenciando a importância do manejo da desfolha precoce como estratégia de controle da $B$. cinerea.

Desta forma os resultados obtidos nesse trabalho demonstram que o manejo da desfolha da variedade Cabernet Sauvignon cultivada em regiões de elevada altitude de Santa Catarina, quando realizado precocemente, anterior ao estádio fenológico virada de cor, reduz a incidência, a severidade e o progresso de $B$. cinerea, sendo, portanto, uma ferramenta útil no Manejo Integrado de Doenças na cultura da videira.

Tendo em visto a estruturação do cacho da videira, segundo Molitor et al. (18), a compactação de cacho é um considerado um importante parâmetro qualitativo da videira, pois cachos compactos são mais suscetíveis ao ataque de $B$. cinerea (10), e quando realizada a desfolha precocemente, as bagas estão em desenvolvimento e o cacho não está completamente compactado, propiciando uma boa aeração e exposição solar do cacho da videira, diminuindo o tempo de molhamento dos cachos, além de favorecer a penetração de produtos fitossanitários no interior dos cachos da videira $(21,22,24)$, visto que a folha torna-se uma barreira física para os fungicidas atingirem o alvo biológico.

Sendo assim, o manejo da desfolha precoce da videira deve ser considerado um manejo corrente do dossel vegetativo, principalmente em regiões úmidas e frias, onde a colheita da uva é muitas vezes determinada pela sanidade da uva, do que, a maturidade propriamente 
dita (17), onde os viticultores devem concentrar seus esforços em melhorar a sanidade da uva para então, alcançar a plena maturidade da uva.

Os resultados desse estudo evidenciam a influência do manejo da desfolha da videira na incidência e severidade da podridão de $B$. cinerea, As desfolhas precoces, realizadas nos estádios fenológicos plena florada, grão chumbinho e grão ervilha, apresentam-se como uma eficiente estratégia de redução da doença nas duas safras avaliadas na variedade Cabernet Sauvignon cultivada nas regiões de elevada altitude de Santa Catarina.

\section{REFERÊNCIAS}

1. Austin, C.N; Wilcox, W. Effects of Fruit-Zone Leaf Removal, Training Systems, and Irrigation on the Development of Grapevine Powdery Mildew. American Journal of Enology and Viticulture, Davis, v.62, n.2, p.193-198, 2011.

2. Baillod, M.; Baggiolini, M. Les stades repères de la vigne. Revue Suisse de Viticulture Arboriculture Horticulture, Nyon, v.25, n.1, p.7-9, 1993.

3. Bondada, B.; Covarrubias, J.I.; Tessarin, P.; Boliani, A.C.; Marodin, G.; Rombolà, A.D. Postveraison Shoot Trimming Reduces Cluster Compactness without Compromising Fruit Quality Attributes in Organically-Grown Sangiovese Grapevines. American Journal of Enology and Viticulture, Davis, v.67, n.2, p.206-211, 2016.

4. Brighenti, A. F.; Brighenti, E.; Pasa, M.S. Vitivinicultura de altitude: realidade e perspectivas. Revista Agropecuária Catarinense, Florianópolis, v.29, supl., p.140-146, 2016.

5. Campbell, C.L.; Madden, L.V. Introduction to plant disease epidemiology. New York: Wiley. 1990. 560 p.

6. De Bem, B.P.; Bogo, A.; Everhart, S.; Casa, R.T.; Gonçalves, M.J.; Marcon Filho, J.L.; Cunha, I.C. Effect of Y-trellis and Vertical Shoot Positioning Training Systems on Downy Mildew and Botrytis Bunch Rot of Grape in Highlands of Southern Brazil. Scientia Horticulturae, Amsterdam, v.185, p.162-166. 2015

7. Gallotti, G.J.; Andrade, E.R.; Sônego, O.R.; Garrido, L.R.; Grigoletti, A. Doenças da Videira e seu controle em Santa Catarina, 2. ed. Boletim Técnico $\mathrm{n}^{\circ}$ 51. Florianópolis: EPAGRI, 2004.

8. Garrido, L.R; Sônego, O.R. Podridão cinzenta da uva: epidemiologia, sintomatologia e controle. Bento Gonçalves: Embrapa Uva e Vinho, 2005. Circular Técnica n. 59.7 p.

9. Hed, B.; Ngugi, H.K.; Travis, J.W. Relationship between cluster compactness and bunch rot in vignoles grapes. Plant Disease, Saint Paul, v.93, n.11, p.1195-1201, 2009.

10. Hed, B.; Ngugi, H.K.; Travis, J.W. Short- and long-term effects of leaf removal and Gibberellin on Chardonnay grapes in the Lake Erie Region of Pennsylvania. American Journal of Enology and Viticulture, Davis, v.66, p.22-29, 2015.

11. Hill, G.; Stellwaag-Kittler, F.; Huth, G.; Schloesser, E. Resistance of grapes in different developmental stages to Botrytis cinerea. Phytopathology, Saint Paul, v.102, n.3, p.328-338, 1981.

12. Hill, G.N.; Beresford, R.M.; Evans, K.J. Tools for accurate assessment of botrytis bunch rot (Botrytis cinerea) on wine grapes. New Zealand Plant Protection, Aukcland, v.63, p.174-181, 2010.

13. Leão, P. C.; Soares, J.M. Implantação do Vinhedo. In. Soares, J.M.; Leão, P.C.S. A vitivinicultura no Semiárido Brasileiro. Brasília, DF: Embrapa Informação Tecnológica; Petrolina: Embrapa Semiárido, 2009.
14. Martin, S.R. Systematic management to minimize botrytis cluster rot in three victorian vineyards. Australian and New Zealand Wine Industry, Auckland, v.5, p.235-237, 1990

15. Martínez De Toda, F.; SAncha, J.C.; Balda, P. Reducing the sugar and $\mathrm{pH}$ of the grape (Vitis vinifera L. cvs. 'Grenache' and 'Tempranillo') through a single shoot trimming. South African Journal of Enology and Viticulture, Stellenbosch, v.34, n.2, p.246-251, 2013.

16. Mcclellan, W.D.; Hewitt, B. Early botrytis rot of grapes: Time of infection and latency of Botrytis cinerea Pers. in Vitis vinifera L. Phytopathology, Saint Paul, v.63, p.1151-1157, 1973

17. Molitor, D.; Behr, M.; Hoffmann, L.; Evers, D. Impact of grape cluster division on cluster morphology and bunch rot epidemic. American Journal of Enology and Viticulture, Davis, v.63, n.4, p.508-514, 2012.

18. Molitor, D.; Baron, N.; Sauerwein, T.; André, C.; Kicherer, A.; Döring, J.; Stoll, M.; Beyer, M.; Hoffmann, L.; Evers, D.. Postponing first shoot topping reduces grape cluster compactness and delays bunch rot epidemic. American Journal of Enology and Viticulture, Davis, v.66, p.164-176, 2014.

19. Mosetti, D.; Herrera, J.C; Sabbatini, P.; Green, A.; Alberti, G.; Peterlunger E.; Lisjak, K.; Castellari, D.S. Impact of leaf removal after berry set on fruit composition and bunch rot in 'Sauvignon blanc'. Vitis, Siebeldingen, v.55, p.57-64, 2016.

20. Poni, S.; Casalini, L.; Bernizzoni, F.; Civardi, S.; Intrieri, C. Effects of early defoliation on shoot photosynthesis, yield components, and grape composition. American Journal of Enology and Viticulture, Davis, v.57, n.4, p.397-407, 2006.

21. Reynolds, A.G.; Schlosser, J.; Sorokowsky, D.; Roberts, R.; Willwerth, J.; De savigny, C. Magnitude of viticultural and enological effects. II. Relative impacts of cluster thinning and yeast strain on composition and sensory attributes of Chardonnay Musqué. American Journal of Enology and Viticulture, Davis, v.58, p.25-41, 2007.

22. Ristic, R.; Downey, M.O.; Iland, P.G.; Bindon, K.; Francis, I.L.; Herderich, M.; Robinson, S.P. Exclusion of sunlight from Shiraz grapes alters wine colour, tannins and sensory properties. Australian Journal Grape Wine Research, Adelaide, v.13, n.2, p.53-65, 2007.

23. Shtienberg, D. Rational management of Botrytis-incited diseases: Integration of control measures and use of warning systems. In: Elad, Y.; Williamson, K.; Tudzynski, P.; Delen, N. (Ed.). Botrytis: biology, pathology and control. Dordrecht: Springer, 2007. pp. 335-347.

24. Tardaguila, J.; Martinez De Toda, F.; Poni, S.; Diago, M.P. Impact of early removal on yield and fruit and wine composition of Vitis vinifera L. Graciano and Carignan. American Journal of Enology and Viticulture, Davis, v.61, n.3, p.372-381, 2010.

25. Tonietto, J.; Carbonneau, A. A multicriteria climatic classification system for grape-growing regions worldwide. Agricultural and Forest Meteorology, Amsterdam, v. 124, p. 81-97, 2004.

26. Wilcox, W.F., Grape disease control. Cornell: Cornell University, 2005. $221 \mathrm{p}$.

27. Wilcox, W.F. Management of grape diseases in the United States. In: $11^{\circ}$ Seminário Nacional sobre Fruticultura de Clima Temperado. Revista Agropecuária Catarinense, Florianópolis, vol. 27, n.2, supl., 2014.

28. Zitter, S.M. The biology and control of Botrytis bunch rot (Botrytis cinerea) in grapevines: ontogenic, physical, and cultural factors affecting initiation and spread of the disease. 2005. Tese (Doutorado) - Cornell University, Cornell.

29. Zoecklein, B.W.; Wolf, T.K.; Duncan, N.W.; Judge, J.M.; Cook, M.K. Effects of fruit zone leaf removal on yield, fruit composition, and fruit rot incidence of Chardonnay and White riesling (Vitis vinifera L.) grapes. American Journal of Enology and Viticulture, Davis, v.43, p.139-148, 1992. 